Institute of Internet and Intelligent Technologies on Automation and Robotics in Construction

Vilnius Gediminas Technical University

June 26-29, 2008

Saulėtekio al. 11, 10223 Vilnius, Lithuania

http://www.isarc2008.vgtu.lt/

ISARC-2008

\title{
AUTOMATED PRODUCTIVITY CONTROL OF LABOR AND ROAD CONSTRUCTION
}

\author{
Ronie Navon \\ National Building Research Institute (NBRI) \\ Faculty of Civil \& Environmental Engineering \\ Technion City, 32000 Haifa, Israel. \\ ronie@technion.ac.il
}

\begin{abstract}
The purpose of the work presented here is to automate productivity measurement so that productivity information will be available on a daily basis, its quality and integrity will be improved and the cost of generating it will be reduced. To do this, the Technion APPC research group started exploring the use of automated data collection (ADC) to measure indirect indicators. This extended abstract focuses on the indicators used for automated labor and earthmoving equipment control.
\end{abstract}

\section{KEYWORDS}

Automation; Data collection; Feedback control; Control methods; Monitoring

\section{INTRODUCTION}

Automated Project Performance Control (APPC) relies on automated measurement, in real-time, of project performance indicators (PPI) - such as cost, schedule, productivity, inputs consumption etc. - using Automated Data Collection (ADC) technologies. This research direction has two major drivers: the increasing need for feedback and monitoring information, and the rapid technological developments in ADC technologies and their declining costs. The Technion - Israel Institute of Technology is engaged in an APPC initiative (Navon 2005; Navon 2007) which deals with automated measurement of various PPI, such as:

- Productivity measurement of labor (Navon and Goldschmidt 2003a; Navon and Goldschmidt 2003b; Navon and Goldschmidt 2008) and earthmoving equipment (Navon et al. 2004;
Navon et al. 2008; Navon and Shpatnitsky 2005; Navon and Shpatnitsky 2006).

- Materials management and control (Navon and Berkovich 2005; Navon and Berkovich 2006).

- Automated safety control (Navon and Kolton 2006a; Navon and Kolton 2006b).

- Using existing tools to automate data collection (Abdelsayed and Navon 1999; Isaac and Navon 2008; Navon and Haskaya 2007).As stated above, this extended abstract focuses on measuring the indirect parameters for labor and earthmoving control. The main technologies that were considered or tested for this purpose are:

- Global Positioning System (GPS) - a position and navigation system that can provide threedimensional positions. For dynamic positioning, 
the principle of differential GPS can be applied in two ways: (1) the differential mode using range measurements, called DGPS, and (2) the differential mode using phase measurements, called "kinematic GPS". Differential GPS (DGPS) can be used to measure locations at a metric or sub-metric accuracy. In kinematic GPS the positions are then computed with a centimetric accuracy. As with DGPS, the kinematic computation can be performed either in post-processing or in real-time, which is called Real Time Kinematic (RTK) GPS.

Being a satellite-based technology, standard GPS needs a line-of-sight between the receiver and the satellite. As such it cannot normally operate indoors. Recent developments enable GPS to operate indoors by adding cellular, laser or other technology.

- Video technology. The use of video cameras has been proposed for construction management, or control purposes e.g. Deng et al. (2001), Abeid et al. (2003), and Wu and Kim (2004). Video cameras can photograph the site in real-time and the manual analysis, or advanced pattern recognition algorithms, can provide valuable data, which can be converted into information regarding progress, or the location of key resources on site. The automated option needs more research in various areas, such as pattern recognition, interpretation of the raw data into meaningful construction management information, integration with other automated data collection methods, and filtering (of the pictures to neutralize varying lighting conditions, or dirt and dust), etc.

- Radio Frequency Identification (RFID). RFID refers to a branch of automatic identification technologies in which radio frequencies are used to capture and transmit data from a tag, or memory chips, embedded or attached to objects. Compared to barcode, RFID is more advantageous, especially for materials tracking, because it has larger data storage capabilities, it is more rugged, it does not require line-ofsight, and it is faster to collect data about batches of components.

\section{LABOR PRODUCTIVITY MEASUREMENT}

Labor productivity is an important PPI. As there is no direct method to automatically measure it, our research proposes to measure an indirect parameter -worker location - and convert it into productivity. The basic concept behind the selection of this indirect parameter is the fact that in order to construct a building element the worker has to be close by. Therefore, knowing the worker's location at a given time, together with additional information, the activity $\mathrm{s} / \mathrm{he}$ is performing can be determined. The time and the worker's location are measured automatically using automated data collection (ADC) technology.

A preliminary model that converts workers' locations into labor productivity and progress was developed (Goldschmidt and Navon 1996; Navon and Goldschmidt 2003a). The model uses two sources of data: (i) the Project Model (PM), which provides data referring to the planned inputs, the schedule and the physical design of the building itself; and (ii) data relating to the actual performance, as measured by the ADC module, which uses ADC technology to measure the location of each worker at regular time intervals. The model converts these locations into actual productivity, to be compared to the planned ones.

In order to determine the feasibility of the above principles, field experiments were carried in three building construction sites (Navon and Goldschmidt 2003a). The main purpose of these experiments was to check the research assumption that the location represents the activity that the worker performs. A positive answer would mean that automated location measurement permits automated evaluation of labor performance. Hence, at that stage the research used "manual location measurement". Encouraged by the results, at the next stage, it was decided to conduct pilot tests whereby the locations would be properly measured. These tests were conducted on two construction sites using GPS as the location measurement technology the results were disappointing.

For the above reasons it was decided to try a video technology - which has been widely used for productivity improvements - at least at the research and development stage. The advantage of this technology is that one recording serves to determine the locations of workers as function of time as well as determining the 
actual work performed at the given time in a separate run. Hence this technology is objective and it permits repetition of the analysis when in doubt. This technology is not limited by the number of workers, or by the number of tasks performed by each worker during the experiment and it is available off-the-shelf.

We are currently considering the usage of RFID technology to replace the location measurement technology. The idea here, though, is not to measure the location of the workers and to associate it to building elements, but to determine which building element the worker works on at each given time. We are planning to conduct experiments - the presentation at the conference will give more details.

\section{EARTHMOVING PRODUCTIVITY MEASUREMENT}

The principles used for labor productivity measurement served as the basis for the earthmoving operations model, which was implemented in a prototype system for controlling road construction operations (Navon and Shpatnitsky 2005; Navon and Shpatnitsky 2006). The model compares the planned to the actual values of productivity. This model, too, has two main sources of data: (i) The Project Model (PM), containing the planned schedule, the planned productivity, and all the data regarding the physical design of the road; and (ii) the Location Measurement Module (LMM), using GPS. This module measures the location of each member of the fleet at regular time intervals. The module records the time of measurement, the identification of the equipment and its location.

This model was realized in a prototype system and tested in the field for three weeks on a road construction site, using GPS mounted on each of the pieces of equipment performing the controlled activities. The productivity of four activities was measured with the prototype system and, at the same time, it was recorded manually so that the accuracy of the model could be assessed. The comparison showed that the deviation between the actual productivity and the one calculated by the prototype was relatively low. These results were encouraging, indicating that automated productiv- ity measurement of earthmoving equipment in road construction is possible. Moreover, the measurement technology (GPS) is available off-the-shelf and affordable.

The above model applied the principles of the model used for labor measurement, namely that the road was divided into predefined work sections (WS). While this assumption is logical in building construction, it is often not the case in road construction. We discovered during the field tests that at the end of each working day we had to manually define the WS. This led to the next stage, whereby a new concept for WE and WS was formed (Navon et al. 2008). Instead of associating locations to activities in a two stage association procedure - as explained in Navon and Shpatnitsky (2005) by predetermining WSs and correspondingly WEs, the algorithm determines the WEs dynamically during its operation, according to the measured locations. Field tests were conducted, where a GPS receiver was installed on the equipment and recorded the measured locations of the equipment. Back in the lab, these locations were fed into the two algorithms, which calculated the productivity - the results of these tests will be presented in the conference.

\section{CONCLUDING REMARKS}

Modern construction management requires up-to-date, relevant, and accurate feedback information from the site regarding the actual productivity - this information is often unavailable, or requires massive manual work. Even when available, this information normally reflects completed events. This unfulfilled need, together with the prospects offered by the rapid improvements in ADC technology, is the major driving force behind the developments in automated PPI measurement.

This extended abstract described developments in automated productivity control of labor and earthmoving equipment. While the GPS was found as a suitable of-the-shelf technology for the purpose of earthmoving equipment control, no of-the-shelf technology was identified for labor control. We are currently testing RFID technology for this purpose - initial results will be presented in the conference. 


\section{ACKNOWLEDGMENTS}

This research was partly supported by THE ISRAEL SCIENCE FOUNDATION (grant No. 444/05). This support is gratefully acknowledged. I would like to thank my colleagues for their invaluable contributions to the research projects mentioned in this extended abstract. They are Y. Doytsher, E. Goldschmidt, S. Khoury, Y. Nishri and Y. Shpatnitsky.

\section{REFERENCES}

[1] Abdelsayed, M., \& Navon, R. (1999) An Information Sharing, Internet-Based, System for Project Control, Civil Engineering and Environmental Systems, Vol. 16, No. 3, 211-233.

[2] Abeid, J., Allouche, E., Arditi, D., \& Hayman, M. (2003) PHOTO-NET II: a Computer-Based Monitoring System Applied to Project Management, Automation in Construction, Vol.12, No. 5, 603616.

[3] Deng, Z., Li, H., Tam, C., Shen, Q., \& Love, P. (2001) An Application of the Internet-Based Project Management System, Automation in Construction, Vol.10, No. 2, 239-246.

[4] Goldschmidt, E., \& Navon, R. (1996) Automated Real-Time Manpower Productivity Control, The Eighth International Symposium on Organization \& Management of Construction, Glasgow, UK, 199-205.

[5] Isaac, S., \& Navon, R. (2008) Feasibility Study of an Automated Tool for Identifying the Implications of Changes in Construction Projects, Journal of Construction Engineering and Management ASCE, Vol. 134, No. 2, 139-145.

[6] Navon, R. (2005) Automated Project Performance Control (APPC) of Construction Projects, Automation in Construction, Vol. 14, No. 4, 467-476.

[7] Navon, R. (2007) Research in Automated Measurement of Project Performance Indicators, Automation in Construction, Vol.16, No. 2, 176-188.

[8] Navon, R., \& Berkovich, O. (2005) Development and On Site Evaluation of an Automated Materials Management and Control Model, Journal of Construction Engineering and Management, ASCE, Vol. 131, No. 2, 1328-1336.
[9] Navon, R., \& Berkovich, O. (2006) An Automated Model for Materials Management and Control, Construction Management and Economics, Accepted.

[10] Navon, R., \& Goldschmidt, E. (2003a) Can Labor Inputs be Measured and Controlled Automatically? Journal of Construction Engineering and Management, ASCE, Vol. 129, No. 4, 437-445.

[11] Navon, R., \& Goldschmidt, E. (2003b) Monitoring Labor Inputs: Automated-Data-Collection Model and Enabling Technologies, Automation in Construction, Vol. 12, No. 2, 185-199.

[12] Navon, R., \& Goldschmidt, E. (2008) Development and Analysis of Worker-Location Measurement Techniques, Journal of Construction Engineering and Management, ASCE, Submitted.

[13] Navon, R., Goldschmidt, E., \& Shpatnitsky, Y. (2004) A Concept Proving Prototype of Automated Earthmoving Control, Automation in Construction, Vol. 13, No. 2, 225-239.

[14] Navon, R., \& Haskaya, I. (2007) Is detailed progress monitoring possible without designated manual data collection? Construction Management and Economics, Vol. 24, No. 12, 1225-1229.

[15] Navon, R., Khoury, S., \& Doytsher, Y. (2008) Dynamic Work Envelop Approach to Automated RoadConstruction Control Journal of Construction Engineering and Management, ASCE, Submitted.

[16] Navon, R., \& Kolton, O. (2006a) Algorithms for Automated Monitoring and Control of Fall Hazards, Journal of Computing in Civil Engineering, ASCE, Submitted.

[17] Navon, R., \& Kolton, O. (2006b) A Model for Automated Monitoring of Fall Hazards in Building Construction, Journal of Construction Engineering and Management, ASCE, Accepted.

[18] Navon, R., \& Shpatnitsky, Y. (2005) Field Experiments in Automated Monitoring of Road Construction, Journal of Construction Engineering and Management, ASCE, Vol. 131, No. 4, 487-493.

[19] Navon, R., \& Shpatnitsky, Y. (2006) A Model for Automated Monitoring of Road Construction, Construction Management \& Economics, Vol. 23, No. 9, 941-951.

[20] Wu, Y., \& Kim, H. (2004) Digital Imaging in Assessment of Construction Project Progress, 21st International Symposium on Automation \& Robotics in Construction, Jeju, Korea, 537-542. 